\title{
Science Versus Public Sentiment: “Covid-19 is not a Bioweapon Created in a Laboratory, Say UK Scientists”, “Nope, Don't Believe It”, Say UK Public.
}

\author{
John Paull \\ University of Tasmania, Hobart, Australia.
}

How to cite this paper: John Paull. (2020) Science Versus Public Sentiment: "Covid-19 is not a Bioweapon Created in a Laboratory, Say UK Scientists”, “Nope, Don't Believe It”, Say UK Public. International Journal of Clinical and Experimental Medicine Research, 4(3), 93-100.

DOI: 10.26855/ijcemr.2020.07.011

Received: June 17, 2020

Accepted: July 12, 2020

Published: July 24, 2020

*Corresponding author: John Paull, University of Tasmania, Hobart, Australia.

Email: j.paull@utas.edu.au; john.paull@mail.com

\begin{abstract}
In the midst of the Covid-19 pandemic, an unresolved question is the aetiology of Covid-19: Where did this novel coronavirus come from? When an account by "UK scientists" ruled out Covid-19 as a bioweapon and as a laboratory creation, the dismissal of the claims by the 'vox pop' was swift and decisive, considered and multifactorial. There was a consensus of public sentiment (of 100\%) to reject the two scientific propositions of "no bioweapon" and "no laboratory involvement". The present paper reports on the top 100 comments (ranked by reader votes and accounting for 13,983 votes, comprising 13,156 up-arrow votes and 827 down-arrow votes) of UK newspaper readers to the dismissal of Covid-19 as a bioweapon and as a laboratory construct. Commentators pointed out the coincidences surrounding the outbreak, especially that the reported ground-zero city of the outbreak, Wuhan, China, was also host to several coronavirus research laboratories. Commentators expressed their skepticism of governments, institutions, and also scientists to tell them the truth (even if those entities knew it). Commentators dismissed the language of the scientists, pointing out (quite rightly) that "improbable" does not equal "impossible". Commentators proposed variously that Covid-19 escaped from a laboratory, was "Made in China", and was a bioweapon. Some readers called for banning the eating of wild animals in China and thereby excluding that channel as a potential viral source in the future. The proximal origin of Covid-19 is presently an unsettled question. Scientists' dismissal of the hypothesis that Covid-19 is a bioweapon or a laboratory construct is itself dismissed by the public. The public want answers but they are also quite ready to question and reject the accounts of scientists. In the meantime, the aetiology of Covid-19 can be expected to remain contested and unsettled for some considerable time.
\end{abstract}

\section{Keywords}

Coronavirus, proximal origin, Wuhan, China, coincidence, trust, gene editing, disruptor, vox pop, public sentiment analysis (PSA) 


\section{Introduction}

Covid-19 is the major disruptor of 2020. Governments around the world have generally been swift to act. Whether the swiftness has been swift enough and whether the actions are the right actions, remains to be seen, on a case by case basis. Such action has often been to lock-down the population and commit massive funds to support the victims of the lock-down, including businesses and the newly unemployed (or furloughed) [1].

An impending question of the moment is: We are locked down, now what? Is it to be: wait for a vaccine; wait for a remedy; exterminate the virus; "let nature run its course"; wait until the virus evolves to a more benign form; or wait and see?

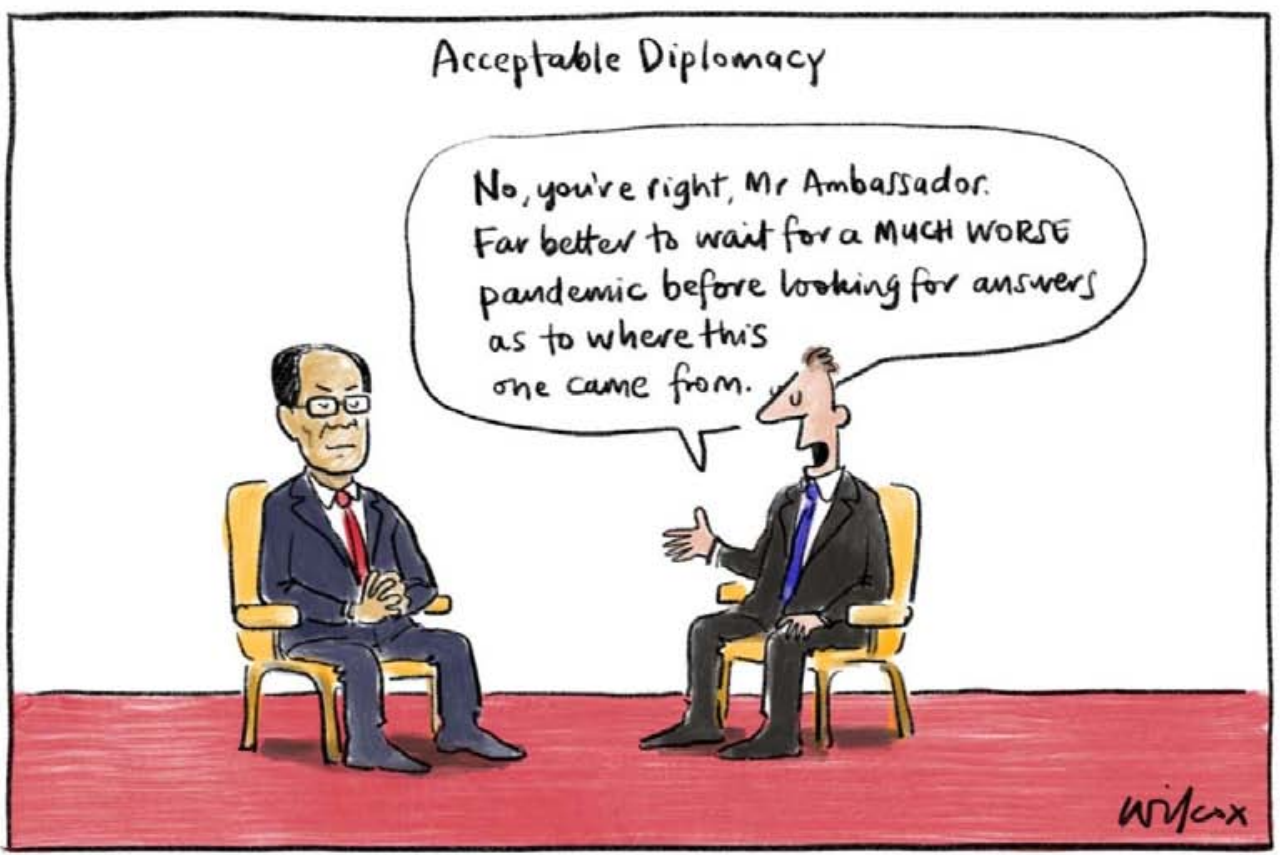

Figure 1. Cartoonist Cathy Wilcox on the origin of Covid-19 (Source: The Sydney Morning Herald, 30 April 2020; with the permission of Cathy Wilcox).

An enduring question is: Where did the virus come from, along with its companion question: How did it get into the human population? (Figure 1). These are presently matters for conjecture. Maybe the virus "escaped from the wild" and is a zoonotic transmission from, say bats, known reservoirs of coronaviruses, or bats via an intermediary species, say pangolins? [2]. Maybe the virus jumped species from such bats or pangolins or other species being sold in a wet market (e.g., a fresh food market) in China in Wuhan [3]? These are conjectures, perhaps even convenient distractions.

Maybe the virus was released from a laboratory, and, in such a case, was the release accidental or intentional [4]? In either case, was an ex-laboratory coronavirus, a "wild" variety, a laboratory evolved variety (say by selective breeding techniques), or a gene-edited virus (a genetically modified (GM) virus) [5]? These are matters of conjecture and for further investigation. If the coronavirus is ex-laboratory, then what was the intent of the hosting laboratory; for research, for potentising the virus for some purpose, for seeking a cure, or for weaponising it [6]? Once again, these are matters of conjecture. At the time of writing, it appears that we are not close to a revelation of the genesis of the novel caronavirus, Covid- 19 .

It is no surprise that authors propose and explore conjectures in the early phases of the Covid-19 pandemic. The world's most deadly pandemic, the Spanish Flu pandemic of 1918-1920, is still, a century later, subject to conjecture and uncertainty, with no agreed proximal origin, no settled mortality data (not even to the closest 10 million deaths), no vaccine and no cure $[7,8]$.

A recent newspaper article ran a headline: "Covid-19 is NOT a bioweapon created in a laboratory, say UK scientists as wild theories sweep the internet" [9]. The newspaper story was an account of a newly published "Letter to the Editor" in Nature Medicine, viz. "The proximal origin of SARS-CoV-2" by Andersen, Rambaut, Lipkin, Holmes and Garry [10]. Despite the Daily Mail headline, the declared country affiliations of the five authors are: USA (n=3); Australia $(n=1)$; and UK $(n=1)$. 
The Andersen et al. [10] letter is strident in its affirmations that: "SARS-CoV-2 is not a laboratory construct or purposefully manipulated virus"; "SARS-CoV-2 is not the product of purposeful manipulation"[10]; and "the SARS-CoV-2 spike protein optimised for binding human-like ACE2 is the result of natural selection” [10]. Those authors conclude: "We do not believe that any type of laboratory-based scenario is plausible" [10].

The Andersen et al. letter is forthright and un-nuanced. It lacks caution at a time when caution is called for, and there is a paucity of supportive data and reasoning for such bold and forthright assertions (in the present author's opinion). There will likely be many who read the letter and find that it falls short of meeting the criteria of either, beyond reasonable doubt or even of, on the balance of probabilities.

The data for settled conclusions is likely to be slowly and painstakingly won from the prevailing cascade of events, over some interval of time in the future (if ever). In the meantime newspaper readers had the opportunity to respond to the "no bioweapon" and "no laboratory" claims, and their responses are the subject of the present paper.

The Daily Mail, to their credit, offer their stories freely on the world wide web, and offer the ready opportunity for any reader to comment on stories and/or to vote comments up or down. In a position statement, the Daily Mail declares its view: "The primary role of the free Press has always been to hold the mighty to account. To fight injustice, to ask searching questions of the rich and powerful, and to represent the interests of ordinary families when the State becomes oppressive or overweening” [11].

\section{Material and methods}

Public sentiment analysis is applied to reveal public attitudes to the aetiology of Covid-19. An account "Covid-19 is NOT a bioweapon created in a laboratory, say UK scientists as wild theories sweep the internet” was published on 19 March, 2020 by a British newspaper, the Daily Mail [9]. The Daily Mail is a leading UK newspaper, it was founded in 1896, it is freely available on the internet, there is no subscription and no barrier to reading the newspaper on line, and the newspaper accepts reader comments on stories (unless there is a legal reason for not, such as a matter is before a court of law). Readers who respond to Daily Mail stories have registered a username and password to login, and have nominated a place and country of residence (which appear associated with any comment) and an email address (which is not published). The Daily Mail has a world-wide readership fostered by the open access policy and the diversification strategy of offering regional versions (e.g. Daily Mail Australia) online. It appears that most stories that appear in the UK version are replicated identically in the Australian edition daily, for example, and the comments are likewise identical and shared, so that the commentariat is international.

For the "Covid is not a bioweapon created in a laboratory" story, there were 639 comments published. The comments for the story were prefaced by the newspaper with the statement: "The comments below have not been moderated" (for some stories the comments are moderated). For articles where comments are unmoderated, comments may appear immediately. Comments may be rejected and fail to appear where they breach the House Rules, such as they are abusive, defamatory, use swear words, are advertising or soliciting etc. [12]. Comments in a story are typically open for several days (after which no further comments can be submitted). Comments can be ranked by readers by: Newest; Oldest, Best rated; and Worst rated. Readers can rate as many comments as they want (once only) with either a green up arrow or a red down arrow and for each comment there are two progressive up-arrow and down-arrow tallies displayed. A submitted comment and a submitted rating cannot be withdrawn. Comments can continue to be rated by readers after comments are closed (at least for some time, and perhaps indefinitely).

For the present paper, the 639 comments of the Covid story were ranked by "Best Rating”. The 100 most popular comments (i.e. highest rated by green-arrowed up votes) were analysed for the present paper to reveal public sentiment. Along with the 100 most popular comments came 97 sub-comments (i.e. comments on commenst), so that a total of 197 comments plus sub-comments were available for the present study. The comments were numbered \#1 through to \#100, and sub-comments (responses to comments) were assigned the corresponding number with a alphabetic-suffix attached, as: \#1a, \#1b, \#2a, etc. The comments were captured by the present author on 12 April 2020 from the Daily Mail web site (www.dailymail.co.uk). The newspaper's tag line after the last comment states: "We are no longer accepting comments on this article". Comments are not (visibly) date stamped and at the time of capture all comments stated " 3 weeks ago" as the time of their submission. For the present paper, comments are referred to by the tuple of: (a) ranking Number; (b) green up-arrow votes; and (c) red down-arrow votes. For example. (\#1: 1247, 53) refers to comment Number 1 which attracted 1247 green up-arrows (positive votes) and 53 red down-arrows (negative votes). 
The 100 comments analysed for the present paper are a sample of comments of self selected commentators $(\mathrm{n}=639)$. The 639 submitted comments were sorted in descending order of reader up-votes and the top 100 comments (which attracted 13,983 votes) are analysed.

An initial semantic content analysis revealed six themes recurring across the 100 comments (viz. coincidences, lack of trust, laboratory, improbable $\neq$ impossible, diet and wild animals, bring manufacturing home). Each comment was then individually rated for mentions of the themes. This procedure was conducted twice, independently, and the results averaged. Some comments mention several themes so the total theme mentions exceeds 100.

\section{Results and discussion}

Public sentiment analysis (PSA) reveals that the public reject the proposition that Covid-19 is not from a laboratory. Newspaper readers (100\%) rejected the claim that "Covid-19 is NOT a bioweapon created in a laboratory". The 100 comments were submitted from seven countries and territories, viz. UK ( $n=71)$; USA ( $n=15)$; Australia $(\mathrm{n}=6)$; Ireland $(\mathrm{n}=4)$; Christmas Island $(\mathrm{n}=2)$; Canada $(\mathrm{n}=1)$; Spain $(\mathrm{n}=1)$. In one way or another each of the comments rejected the proposition. The 100 comments attracted 13,983 votes, comprising 13,156 positive votes (94\%) and 827 negative votes (6\%).

Reader votes ranged from the high of (Comment \#1: 1247 up votes, 53 down votes) through to the low of (\#100: 46, 0). The 100 comments attracted 97 sub-comments (comments on a comment), some comments attracted no sub-comments, and the maximum number of sub-comments for an individual comment was two. Sub-comments attracted far fewer votes, up or down, than comments. Sub-comments generally affirmed and/or elaborated comments.

In dismissing the "no bioweapon" and "no laboratory" hypotheses, the coincidence-retort was popular. Many commenters pointed out the coincidence of Wuhan being the locus of the outbreak as well as the host of several coronavirus research laboratories. Researchers in China have made the same point, nominating the Wuhan Center for Disease Control \& Prevention and the Wuhan Institute of Virology, Chinese Academy of Sciences [13]. Coincidence is not causation and no commentators suggested it was, but coincidence may serve the function of indicating where a light might productively be shone. Comments are generally brief and so, where quoted, are typically quoted in their entirety. Where comments have been trimmed in the present paper, this is indicated by the insertion of ellipses (...).

A semantic analysis of the 100 comments reveals six recurring themes in the comments (Figure 2). "Laboratory" was the most recurrent theme with $38 \%$ of comment themes mentioning the theme "laboratory", or "bioweapon", or that the virus is "manufactured", or "Made in China" (\#7: 441, 29). Thirty two percent of comment themes refer to a skepticism and lack of trust in what governments or scientists would claim, e.g.: "Well, they would say that, wouldn’t they" (\#95: 49, 3); "If they knew for certain it was we would not be told” (\#97: 47, 0); "Wonder how much and by whom they were paid to say that?” (\#98, 47, 1).

Fifteen percent of comment themes referred to coincidences, especially the coincidence of Wuhan being the locus of the outbreak and the host of several related laboratories: e.g.: "So it's just a coincidence that the very town where this all started has a viral lab? Pull the other one!” (\#68: 61, 6).

Nine percent of comment themes related to diet, bats, eating wild animals etc, e.g.: "When we recover from this the world must put maximum pressure on China to cease eating everything that moves" (\#60: 67, 14). Four percent of comment themes were to the effect that "improbable does not equal impossible", e.g.: "So that's improbable not impossible" (\#94: 49, 0). Three percent of comments related to manufacturing themes, and called for the repatriation of manufacturing from China, e.g.: “... we need to fatten up our manufacturing base here at home” (\#15: 185, 12).

The first 12 comments are reported below. They raise the dominant and recurring issues of the 100 comments, including that of "Too many odd coincidences" (\#2: 806, 33), "It’s suspicious” (\#4: 620, 22), "If it looks like a duck" (\#6: 486, 14), government secrecy and lack of trust in government and defence to tell the truth (\#3b, 5, 0), the lesson of "returning industries back home (\#12: 215, 2). Several raise leads to UK defence research, Porton Down (\#1b: 69, 14) and a US-Wuhan research linkage that is subject to current legal action $(\# 9: 327,6)[14,15]$.

The \#1 comment stated that: "What a coincidence out of China's 3.7 million square miles territory, this bug popped up right next to the Wuhan bio-lab!” (\#1: 1,247, 53. A response added “And the Wuhan Military Games 2019 were held end of October. Read the Wiki page" (\#1a: 88, 2). Another response added: "Porton Down is only 13 miles from Salisbury"(\#1b: 69, 14). Porton Down is "Britain's secret weapons research facility", employs 3,000 people, occupies 7,000 acres, and "was created 100 years ago in response to the German gas attacks of World War One" [14]. 
Too many coincidences, stated the \#2 comment: "Not sure I believe this. Too many odd coincidences with the lab in Wuhan, etc. If they WERE trying to engineer bioweapons that had a delayed immune response, so a disease could infect a whole nation before anyone noticed, and everyone got sick at once... then they might not have realized it escaped containment until it was too late. I really detest being labeled a kook for wondering about perfectly reasonable scenarios. Look up Harvard scientist arrested and make up your own mind” (\#2: 806, 33). The writer is referring to Professor Charles Lieber, Chair of the Department of Chemistry and Chemical Biology at Harvard University, recently arrested (along with two Chinese nationals, Yanqing Ye and Zaosong Zheng) for lying about his Wuhan laboratory activities [15]. Also see comment \#9 below.

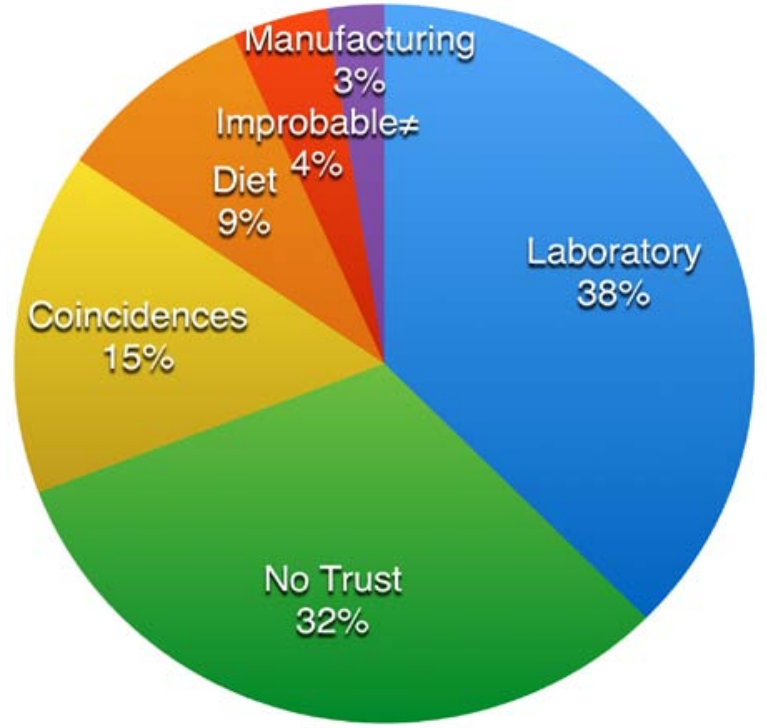

Figure 2. Analysis of the semantic content of newspaper reader comments (6 themes: laboratory, lack of trust, coincidences, diet/wild animals, improbable $\neq$ impossible, bring manufacturing home).

"Not natural" stated the \#3 comment: "The doctor in China who told the world about the virus and later died, stated he was nearly certain this was not a natural virus" (\#3: 680, 26). A sub-comment added: "If it was engineered would the governments really tell the common folk. It would create more panic and they would gain nothing from telling us the truth anyway” (\#3b: 5, 0).

In a strong rebuke of the Andersen et al. 2020 paper, the \#4 comment stated: "No-one can straight up DENY it wasn’t made in Lab. It’s “improbable” \& "highly unlikely” ... These words are not flat out denial. Minimal percentage chance,-_it could have been created or mutated in a lab... It’s Suspicious” (\#4: 620, 22).

The \#5 comment declared: "It's a bio-weapon, made in China, from SARS virus splices stolen from Canada ..." (\#5: 527, 45). The \#6 comment reiterated the point that the corona events are suspicious: "If it looks like a duck, etc. This may not be biological warfare, but if it isn't biological warfare it sure ticks all the boxes" (\#6: 486, 14).

The \#7 comment stated succinctly: "Made in China” (\#7: 441, 29). This was contradicted by a response: “Actually Made in America” (\#7a: 72, 185). Of the 197 responses in the data set, it was the least popular.

The \#8 comment raised the issue of the public distrust of the prevailing secrecy of government, defence and laboratories. "As if anyone would admit it if it were a bioweapon? Are people throwing all logic out the window just because they're quarantined?”(\#8: 377, 9).

The \#9 comment raised an interesting juxtaposition of current legal actions relating to US-Wuhan academic interactions. "Charles Lieber, Harvard professor, set up and ran the Wuhan biotech lab. Search and read. The story goes Alice in Wonderland mode” (\#9: 327, 6). The US Department of Justice states that: "Dr. Charles Lieber, 60, Chair of the Department of Chemistry and Chemical Biology at Harvard University, was arrested this morning and charged by criminal complaint with one count of making a materially false, fictitious and fraudulent statement ... Lieber became a "Strategic Scientist" at Wuhan University of Technology (WUT) in China and was a contractual participant in China's Thousand Talents Plan ... These talent programs seek to lure Chinese overseas talent and foreign experts to bring their knowledge and experience to China and reward individuals for stealing proprietary information. Under the terms of Lieber's three-year Thousand Talents contract, WUT paid Lieber 
$\$ 50,000$ USD per month, living expenses of up to 1,000,000 Chinese Yuan (approximately \$158,000 USD at the time) and awarded him more than \$1.5 million to establish a research lab at WUT” [15].

Comments \#10 and \#12 both raised issues of manufacturing sovereignty and lessons that might be learned. "For a country to threaten another country by saying they will withhold the ingredients for making vital medicine says it all” $(\# 10,312,7)$. "One thing is blatantly obvious, bio weapon or not, the stupidity of relying on a country on the otherside of the world for everything including basic medical equipment and medicines is now laid bare. Governments need to start returning industries back home” (\#12: 215, 2).

The eleventh comment reiterated the coincidence of the outbreak city and its coronavirus laboratories. "Just so happens that in Wuhan there is a place called Wuhan Institute of Virology. And guess what: They have been researching SARS Coronavirus in Horseshoe Bats. Come on, reality check here. Coronavirus breaks out in a Chinese city that most of us has never heard of and it just so happens that the city is home to a laboratory doing research on the SARS Coronavirus. I'm no conspiracy theorist but this is screaming accidental outbreak to me” (\#11: 217, 6).

A later comment linked the issues of coincidences and distrust of government: "Too many coincidences. Too many beneficial coincidences at that. Who knows how it was released, but one thing is for sure, Governments will never be straight with you” (\#16: 159, 4).

Another comment rebuked Andersen et al. [10] for over-stating their case. "Improbable is not the same as impossible" (\#17: 145, 2). Another comment indicated we need whistleblowers: "Even if it was they would never admit to it, this is why we need people like Assange to expose the truth” (\#18: 136, 4). The US is presently trying to extradite Julian Assange from Britain for truth telling [16].

Further comments reiterated the issues of coincidence and institutional secrecy. "Of course it is just coincidence that the virus started in Wuhan where China has had a germ lab for 64 years. Tell me China is not trying to develop bio weapons” (\#20: 126, 10) and “... there’s something sinister about this that makes me doubt we are being told the whole truth. Maybe the truth is too scary to be told?” (\#21: 117, 6).

Of the headline proposition that "Covid-19 is NOT a bioweapon created in a laboratory, say UK scientists", one comment stated crisply: “They're wrong” (\#74: 59, 7), while another stated frankly: “Nope, don’t believe it” (\#39, $84,6)$.

Only the final comment was not classified as any of the above six themes, and instead expresses some wonderment: "You must admit that for a simple virus the world's governments and general populations have been thrown into total chaos in very quick order. Billions being found by banks — where from? Not to make light of the situation but-WOW” (\#100: 46, 0).

The commentators of the present study have been forthright in rejecting the proposition of scientists, while the scientists have been forthright in their own apologetics. Where does the truth lie? Faith in the "wisdom of crowds" underpins faith in democratic processes $[17,18]$. Such faith does not mean that crowds will reach the best or correct conclusion, and needs to be offset by consideration of the "stupidity of crowds" [19], and perhaps even the "madness of crowds" [20]. The "wisdom of experts" is an alternative stratagem to invoke, but it is also a flawed wisdom where "almost daily, some expert's previous certainty is discredited" [21]. Where the truth lies in the Covid-19 scenario, only time will tell, and perhaps not even then.

\section{Conclusions}

Public sentiment, as manifested by newspaper readers, categorically rejected the proposition that: "Covid-19 is NOT a bioweapon created in a laboratory". Commentators provided a variety of reposts to the proposition. None of the 100 commentators supported the proposition. The commentators are of a single opinion that the case of Andersen et al. [10] has not been made beyond a reasonable doubt, and nor has it been made on the balance of probabilities, and, frankly, they do not believe it. The commentariats are in consensus in rejecting the proposition. Readers were inclined to reflect the view that "the truth is rarely pure and never simple" [22].

Just what is true, possible, and impossible regarding the origin of Covid-19 is contested. Sherlock Holmes instructed Watson: "apply my precept ... when you have eliminated the impossible, whatever remains, no matter how improbable, must be the truth” [23]. Applying the precept for Covid-19 is proving an ongoing challenge.

The commentariat of newspaper readers state unequivocally that they are not at all convinced of the claim of "Covid-19 is NOT a bioweapon created in a laboratory". In any event it would appear to be far too early in the play-out of the Covid-19 virus to be unequivocal regarding the origin. The claims of Covid-19 as a bioweapon or not, as created in a laboratory or not, require further scrutiny, further enquiry, and more data, rather than the strident proclamations and denialism of Andersen et al. [10], so say the people. 
The present paper demonstrates the use of public sentiment analysis (PSA) via newspaper comments. The commentators are a self-selected group who are engaged with the topic under consideration (sufficiently engaged to take action in responding to a published article). This is in contrast to randomly sampled subjects of surveys, questionnaires and focus groups who may have little of no engagement with, care of, or interest in, a particular topic for which they are recruited to comment.

In the fullness of time, the 'received wisdom' of the past is felled. The digital revolution and the resulting democratisation and broadening of the science commentariat (as exemplified in the present paper), can accelerate the process of questioning science. That will be an irritant to some scientific incumbents, but it nevertheless augurs well for science and the future for scientists to be subject to broader public oversight and not just peer review but also public review.

Skepticism is a key tenet of science [24]. The present paper demonstrates that skepticism regarding claimed or excluded causalities (for Covid-19 in this instance) is 'alive and well' in the cohort of newspaper readers, who offer robust commentary and critique, and that is a cause for celebration. The aetiology of the Spanish Flu pandemic was never consensually settled, even after the passing of a century. In the case of Covid-19 the aetiology can be expected to remain contested and unsettled for some considerable time.

\section{Acknowledgements}

The Daily Mail and its commentariat and vote-casting readers are acknowledged for providing an insight into public sentiment regarding Covid-19 and its origins. The Daily Mail newspaper is to be commended for adopting an open access policy (rather than a pay wall model) and for hosting a robust comments section for almost every one of their stories.

\section{References}

[1] Milliken, D. (2020). UPDATE 1-UK to set out future of costly coronavirus furlough scheme on Tuesday. Reuters, 2020.12 May (www.reuters.com).

[2] Briggs, H. (2020). Coronavirus: The race to find the source in wildlife. BBC News, 2020. 25 February (www.bbc.com).

[3] Woodward, A. (2020). Both the new coronavirus and SARS outbreaks likely started in Chinese wet markets. Photos show what the markets look like. Business Insider Australia, 2020. 23 January (www.businessinsider.com.au).

[4] Rincon, P. (2020). Coronavirus: Is there any evidence for lab release theory? BBC News, 2020. 1 May (www.bbc.com).

[5] Chan, V. S. W. (2006). Use of Genetically Modified Viruses and Genetically Engineered Virus-Vector Vaccines: Environmental Effects. J Toxicol Environ Health A, 69(21): 1971-77.

[6] Bertrand, N., D. Lippman, and L. Seligma. (2020). Officials probe the threat of a coronavirus bioweapon. Politico, 2020.23 April (www.politico.com).

[7] Barry, J. M. (2018). The Great Influenza: The Story of the Deadliest Pandemic in History. 2018, (Updated edition). New York, NY: Penguin Books.

[8] Brown, J. (2018). Influenza: The Hundred-year Hunt to Cure the Deadliest Disease in History. 2018, New York, NY: Touchstone.

[9] May, L. (2020). Covid-19 is NOT a bioweapon created in a laboratory, say UK scientists as wild theories sweep the internet. Daily Mail, 2020. 19 March.

[10] Andersen, K. G., et al. (2020). The proximal origin of SARS-CoV-2. Nat Med, 2020. 26: p. 450-452. < https://doi.org/10.1038/s41591-020-0820-9 >.

[11] Daily Mail. (2020). DAILY MAIL COMMENT: The failure to protect our valiant NHS staff is a tragedy. But now we can ALL do our bit. Daily Mail, 2020. 29 April.

[12] Daily Mail. (2020). House Rules. Daily Mail, 2020. <www.dailymail.co.uk/home/house_rules.html>.

[13] Xiao, B. and L. Xiao. (2020). The possible origins of 2019-nCoV caronavirus. February. preprint,: DOI: 10.13140/RG.2.2.21799.29601, 2020.

[14] Mosley, M. (2016). Inside Britain’s secret weapons research facility. BBC News, 2016. 28 June.

[15] Department of Justice. (2020). Harvard University Professor and Two Chinese Nationals Charged in Three Separate China Related Cases. 2020, Press Release \#20-99, 28 January. Washington, DC: The United States Department of Justice.

[16] Keane, D. (2020). Julian Assange secret recordings a potential “lifeline”, barrister Geoffrey Robertson says. ABC News, 2020. 24 February. https:/www.abc.net.au/news/2020-02-24/geoffrey-robertson-responds-to-julian-assange-secret-recording/ 11993792.

[17] Surowiecki, J. (2004). The Wisdom of Crowds: Why the Many Are Smarter Than the Few and How Collective Wisdom Shapes 
Business, Economies, Societies and Nations. 2004, New York: Doubleday.

[18] Blagden, D. (2019). Do Democracies Possess the Wisdom of Crowds? Decision Group Size, Regime Type, and Strategic Effectiveness. International Studies Quarterly, 2019. 63(4): 1192-1195.

[19] Rees, A. (2017). The stupidity of crowds. Open for Ideas, 2017(12 April): p. openforideas.org.

[20] Murray, D. (2019). The Madness of Crowds: Gender, Race and Identity. 2019, London: Bloomsbury Continuum.

[21] King, A. A. (2018). Think Critically About the Wisdom of Experts. MIT Sloan Management Review, 2018.26 November (Winter).

[22] Wilde, O. (1899). The Importance of Being Earnest, A Trivial Comedy for Serious People. 1899, London: Chiswick Press.

[23] Conan Doyle, A. (1890). The SIgn of Four. 1890, London: Spencer Blackett.

[24] Shermer, M. (2009). What Skepticism Reveals about Science: A skeptic's journey for truth in science. Scientific American, 2009. 1 July (www.scientificamerican.com). 